Cochrane Database of Systematic Reviews

\title{
Written and verbal information versus verbal information only for patients being discharged from acute hospital settings to home
} (Review)

Johnson A, Sandford J, Tyndall J

Johnson A, Sandford J, Tyndall J.

Written and verbal information versus verbal information only for patients being discharged from acute hospital settings to home.

Cochrane Database of Systematic Reviews 2003, Issue 4. Art. No.: CD003716.

DOI: 10.1002/14651858.CD003716.

\section{www.cochranelibrary.com}


TABLE OF CONTENTS

HEADER

ABSTRACT

PLAIN LANGUAGE SUMMARY

BACKGROUND

OBJECTIVES

METHODS

RESULTS

DISCUSSION

AUTHORS' CONCLUSIONS

ACKNOWLEDGEMENTS

REFERENCES

CHARACTERISTICS OF STUDIES

DATA AND ANALYSES

Analysis 1.1. Comparison 1 Verbal and written information v verbal information, Outcome 1 Knowledge.

Analysis 1.2. Comparison 1 Verbal and written information v verbal information, Outcome 2 Satisfaction.

Analysis 1.3. Comparison 1 Verbal and written information v verbal information, Outcome 3 Use of outpatient treatment.

Analysis 1.4. Comparison 1 Verbal and written information v verbal information, Outcome 4 Use of telephone advice. APPENDICES

WHAT'S NEW

HISTORY

CONTRIBUTIONS OF AUTHORS

DECLARATIONS OF INTEREST

SOURCES OF SUPPORT

INDEX TERMS 
[Intervention Review]

\section{Written and verbal information versus verbal information only for patients being discharged from acute hospital settings to home}

Anne Johnson ${ }^{1}$, Jayne Sandford ${ }^{1}$, Jessica Tyndall2

1Department of Public Health, School of Medicine, Flinders University, Adelaide, Australia. ${ }^{2}$ Gus Fraenkel Medical Library, Flinders University, Adelaide, Australia

Contact address: Anne Johnson, Department of Public Health, School of Medicine, Flinders University, GPO Box 2100, Adelaide, South Australia, 5001, Australia. anne.johnson@flinders.edu.au.

Editorial group: Cochrane Consumers and Communication Group

Publication status and date: Edited (no change to conclusions), published in Issue 1, 2010.

Citation: Johnson A, Sandford J, Tyndall J. Written and verbal information versus verbal information only for patients being discharged from acute hospital settings to home. Cochrane Database of Systematic Reviews 2003, Issue 4. Art. No.: CD003716. DOI: 10.1002/14651858.CD003716.

Copyright $\odot 2010$ The Cochrane Collaboration. Published by John Wiley \& Sons, Ltd.

\section{A B S T R A C T}

\section{Background}

It is becoming commonplace for patients to be discharged earlier from acute hospital settings to their own homes and be required to manage various aspects of their own care. This has increased the need for detailed information to be given to patients and/or significant others to enable them to effectively manage care at home. It has been suggested that providing written health information can assist in this self management.

\section{Objectives}

To determine the effectiveness of providing written health information in addition to verbal information for patients and/or significant others being discharged from acute hospital settings to home.

\section{Search methods}

Computerised searches from 1990 to September 2005 in the Cochrane Consumers and Communication Review Group Specialised Register and Cochrane Central Register of Controlled Trials (CENTRAL), MEDLINE (Ovid), EMBASE, CINAHL, PsycINFO, ERIC, OVID (including Ageline, EBM Reviews, DARE, Best Evidence, Pre-MEDLINE and PsycARTICLES), Sociological abstracts, Austhealth and bibliographies in articles that met inclusion criteria.

\section{Selection criteria}

Articles were selected if they were randomised control trials or controlled clinical trials; included patients discharged from acute hospital settings to home; the patient and/or significant others received written health information and verbal information in the intervention group, and verbal information only in the control group; and the intervention (written health information and verbal information) was provided at discharge.

\section{Data collection and analysis}

Two review authors independently screened abstracts to determine relevance. Relevant full paper copies were then reviewed against the inclusion criteria. The findings were extracted by one author and confirmed by the other author. The two trials that met the inclusion criteria were too disparate to warrant meta-analysis. 


\section{Main results}

The participants in the two trials were parents of children who were discharged from children's hospitals, one in the United States ( $n=197)$ the other in Canada $(n=123)$. Provision of verbal and written health information significantly increased knowledge and satisfaction scores.

\section{Authors' conclusions}

This review recommends the use of both verbal and written health information when communicating about care issues with patients and/ or significant others on discharge from hospital to home. The combination of verbal and written health information enables the provision of standardised care information to patients and/or significant others, which appears to improve knowledge and satisfaction. Many of our objectives could not be addressed in this review due to lack of trials which met the review's inclusion criteria. There is therefore scope for future research to investigate the effects of providing verbal and written health information on readmission rates, recovery time, complication rates, costs of health care, consumers' confidence level, stress and anxiety and adherence to recommended treatment and staff training in the delivery of verbal and written information. In addition there are other factors which impact on the effectiveness of information provided that were not considered in this review but are worthy of a separate systematic review, such as the impact of patient and/or significant others being involved in the development of the written information and cultural issues around development and provision of information. Due to concerns about literacy levels for some population groups, other systematic reviews should also focus on other modes of delivery of information besides the written format.

\section{PLAIN LANGUAGE SUMMARY}

\section{Written and verbal information, compared to verbal information only, for people being discharged from hospital}

When children are discharged from hospital, parents' understanding of how to continue care at home is better if they receive both written and verbal information.

When people are discharged from hospital, they and/or their carers are given information on how to manage care effectively at home. Hospital staff usually explain what is required verbally and may also give written, or even video-taped, information. The review of hospital discharge information found only studies looking at parents caring for their children. Parents had a better understanding of the care needed when given both written and verbal instructions, rather than verbal instructions alone. Further research is needed to determine if this leads to better health outcomes and faster recovery times, and on discharge information for other hospital patients. 


\section{B A C K G R O U N D}

It is becoming commonplace for patients to be discharged from acute hospital settings to their own homes following an episode of in-patient care, a same day admission or a visit to an emergency department, and be required to manage various aspects of their own care at home or have significant others (family members or other people important to that person's care and wellbeing) provide that care. This coupled with the decreasing lengths of hospital stay in in-patient care has increased the need for more detailed information to be given to patients and/or significant others so that they can effectively manage their care at home. For example, Organisation for Economic Cooperation and Development health data (OECD 2001) shows an international trend for a decrease in the average length of stay in in-patient care since the early 1990s. The majority of in-patients are now being treated in hospital for the minimum amount of time. This is in response to pressure to contain rising health costs within hospital-based services (Nutbeam 1991), and advances in medical and surgical treatments. Patients who had previously remained in hospital for days are now able to leave hospital a few hours after their procedure (Voepel-Lewis 1992).

These changes in health policy have significant impact on the practices of staff, but also result in a significant shift in responsibility, knowledge, and cost to patients and/or significant others. The transfer of care after discharge from an acute hospital setting to home care by the patient and/or significant others has meant that timely and effective delivery of information about that care has to be provided by staff and delivered in a format that ensures effective transfer of information and responsibility. Health professionals now often have much shorter time periods to inform patients and/or significant others on how to perform self care following discharge from hospital (Leino-Kilpi 1993). To have access to comprehensive written information about care and treatment after discharge from an acute hospital setting, in a format that the patient and/or family member can understand, is a basic right for all health consumers (user of the service and/or significant others) (SAHC 1996). There is a growing demand from consumers of hospital services to be provided with spoken, written, pictorial or recorded information that will help them participate effectively in their own 'after care' and be able to make the best health choices for themselves and family members.

In response to this demand there has been a growing awareness among health professionals of the need to provide information to health consumers in a format that best meets their individual needs. These formats can include verbal and written instructions, audiotapes, videotapes, follow up phone calls, e-mail communication with their doctor; and websites to access further information. These delivery formats contrast to the provision of verbal information only at the time of discharge, which is an approach that leaves knowledge and authority in the hands of health professionals. It also has the potential to disempower consumers, as they are unable to refer to information after discharge or may not remember what they have been told (Linke 1996).

It has been suggested that providing written information to consumers about 'after care' is one important strategy which has the potential to reduce demands on health services through more appropriate use of services (Fries 1998); improve confidence of consumers to manage their own care (or the care of a family member) and seek appropriate follow up care (Johnson 1999); decrease recovery time (Johnston 1993; Devine 1995); improve satisfaction with services provided whilst in hospital (Larson 1996); decrease stress and anxiety (NHMRC 2000); reduce hospital readmissions (Fries 1998; Mamon 1992) and improve adherence to hospital aftercare regimes (Frith 1991; Gibbs 1989; Mazzuca 1982). However, there has been a degree of doubt among some health professionals regarding the benefits of providing this type of written information to consumers and whether it serves any real purpose, or is just 'a nice thing to do' (Johnson 1999). These doubts have been amplified by recognition of the cost of providing such resources to consumers, especially in the current economic climate facing hospitals. It is acknowledged that the provision of written information to consumers after an episode of care in an acute hospital setting is one of the many factors which may, in isolation or combination, impact on health outcomes and service utilisation and satisfaction (Henderson 2001; Leino-Kilpi 1993).

This systematic review sought to answer some of the questions raised about the benefits of providing care information on discharge to consumers in the written format, for example pamphlet, booklet or information sheet, in combination with providing verbal instructions, as opposed to providing verbal instructions only. While there are a number of delivery formats available to provide health information, for example pictorial, recorded (video and audio), counselling, follow up telephone calls, e-mail communications and the internet, the written format in addition to verbal instruction was specifically chosen as the focus for this review because it is the most common approach used in hospital settings at discharge. The effectiveness and benefits of using these alternative information delivery formats need to also be determined through separate systematic reviews.

\section{O B JECTIVES}

To determine the effectiveness of providing written health information in addition to verbal information for patients and/or significant others being discharged from acute hospital settings to home.

The following questions and comparisons were considered in conducting the review:

\section{Primary research questions}

Does the provision of written health information improve patient health outcomes?

1. Effect of the provision of written health information with verbal information on readmission rates compared to verbal information only.

2. Effect of the provision of written health information with verbal information on recovery time compared to verbal information only. 3. Effect of the provision of written health information with verbal information on complication rates compared to verbal information only.

Does the provision of written health information reduce overall costs of health care?

4. Effect of the provision of written health information with verbal information on community service costs, compared to verbal information only. 
5. Effect of the provision of written health information with verbal information on outpatient service care costs compared to verbal information only.

6. Effect of the provision of written health information with verbal information on inpatient service care costs compared to verbal information only.

Does the provision of written health information improve psychosocial outcomes?

7. Effect of the provision of written health information with verbal information on patient and/or significant others knowledge compared to verbal information only.

8. Effect of the provision of written health information with verbal information on confidence in one's own care management compared to verbal information only.

9. Effect of the provision of written health information with verbal information on stress and anxiety compared to verbal information only.

10. Does the provision of written health information with verbal information improve satisfaction with inpatient services provided prior to discharge compared to verbal information only?

11. Does the provision of written health information with verbal information improve adherence to recommended care compared to verbal information only?

\section{Secondary research questions}

12. Do the circumstances under which the written health information with verbal information is provided influence the outcomes?

13. Does the person providing the written health information with verbal information influence the above outcomes?

14. Does the environment in which the written health information with verbal information is provided influence the above outcomes? 15. Does the time before discharge in which the written health information with verbal information is provided influence the above outcomes?

\section{METHODS}

\section{Criteria for considering studies for this review}

\section{Types of studies}

- Randomised controlled trials

- Controlled clinical trials

\section{Types of participants}

- All patients discharged from an acute hospital setting to home (excluding hostels, nursing homes and convalescence homes)

- All ages

- Patient and/or significant others (including parents of children)

\section{Types of interventions}

Format of information

- Written discharge information (printed) and verbal information compared with verbal information only

- Verbal information is focused on verbal instruction about care

Timing of information provision
- At time of discharge

Types of information

- Disease/condition management information

- Specific care information related to procedures

- Medication information

- Advice on when to seek attention

- Advice on who to seek attention from and how

\section{Types of outcome measures}

1. Readmission rates

2. Recovery times

3. Patient/carer (family member or significant other) knowledge

4. Complication rates

5. Service utilisation and costs (community, outpatient, and inpatient)

6. Confidence in one's own care management

7. Stress and anxiety levels

8. Patient/carer (family member or significant other) satisfaction with services provided prior to discharge

9. Adherence to recommended care

\section{Search methods for identification of studies}

For the first iteration of this review, we searched databases for the period 1990 to 2002. For the review update, the original MEDLINE (Ovid) search was re-run with minor technical, but no substantive changes (2002 to Week 1 September 2005), as presented at Appendix 1.

We used appropriate variations of the above search strategy were utilised to search the following electronic databases:

- Cochrane Consumers and Communication Review Group Specialised Register and Cochrane Central Register of Controlled Trials (CENTRAL, The Cochrane Library) (Searched September 2005)

- Ageline (2002 to September 2005)

- ERIC (2002 to September 2005)

- Social Services Abstracts (2002 to September 2005)

- Sociological Abstracts (2002 to September 2005)

- AMED (Allied and Complementary Medicine) 1985 to September 2005

Studies that were identified through the above search strategy and appeared to meet the inclusion criteria (ie. included and excluded studies) were retrieved in full and their reference lists examined to identify any additional studies that met the inclusion criteria.

\section{Data collection and analysis}

There were five stages to the review process. Throughout the review process review authors were not blinded to trials.

Stage 1: Two review authors (AJ, JS) screened the abstracts of articles identified from the search strategy. Any disagreement regarding relevance of the abstracts was resolved through discussion. Full paper copies of articles were obtained and examined where there was insufficient information in the abstracts. 
Stage 2: Two review authors (AJ, JS) independently examined full paper copies of articles and determined whether they fulfilled the inclusion criteria. The articles needed to fulfil all five inclusion criteria which were:

- Randomised controlled trial or clinical controlled trial

- Discharged from an acute hospital setting

- Discharged to home

- Intervention must be written discharge care information plus verbal information only

- Intervention must be provided at discharge to home only

Any disagreements regarding inclusion were resolved by discussion.

Stage 3: Data was extracted from relevant trials using a data collection tool independently by each review author (AJ and JS) and then data were compared. Data extracted included: study population, study methods, interventions, assessment of outcomes, results, conclusions and limitations. Authors were contacted for further information as required. Any disagreements regarding information extracted were resolved by discussion.

\section{Stage 4: Assessment of validity}

Allocation concealment was used to assess validity, by asking 'Was allocation concealment adequate?'

This was described as adequate (A), unclear (B), inadequate (C), or that allocation concealment was not used (D). A sensitivity study was planned to be performed to exclude trials that were in the (C) and (D) categories. This was not necessary due to the included trials fulfilling categories (A) or (B).

\section{Stage 5: Analysis}

The primary analysis was a comparison of written health information and verbal information versus verbal information only for each of the questions outlined in the objectives of the review. All comparisons that were made are narratively described and presented in tables. Where methodological processes differed no meta-analysis was undertaken. As a consequence no sensitivity analyses were required.

\section{Consumer participation:}

The overall focus for this review was initially recommended by an editor of the Cochrane Consumers and Communication Review Group, and taken up and shaped by the current review authors.

The focus of this review as it relates specifically to the needs of the health services and health professionals is on reducing overall costs of health care, adhering to treatment regimes, improving satisfaction with care, improving health outcomes and reducing demands on health services.

Consumers' perspectives have broadened the focus of this review to also address knowledge, confidence, stress and anxiety. This has been determined by:

- the importance to consumers of having written information to refer to during consultation with hospital staff in preparing for discharge, and then as a reference tool after discharge;

- consumers' beliefs that health information enhances knowledge and confidence in managing care at home after discharge, and reduces stress and anxiety related to being uncertain of what to do.
The review authors' understanding of these consumer perspectives, and their commitment to integrating them into the review, came from:

1. Reports in the literature, primarily of qualitative researchers presenting consumer views;

2. Anne Johnson's qualitative research on health information and the benefits to consumers and the needs of parents of children being discharged from hospital to home;

3. Anne Johnson's discussions with health professionals and consumers whilst working at the Women's and Children's Hospital, Adelaide and the National Resource Centre for Consumer Participation in Health, Melbourne; and

4. Jayne Sandford's discussions with consumers involved as members of a Health Information Reference Group at Flinders Medical Centre, Adelaide.

In addition, consumers were involved as external peer reviewers during the editorial process, through the Consumers and Communication Review Group.

\section{RES U L T S}

\section{Description of studies}

Electronic searching yielded a total of 1795 citations in the first review (to 2002) and 478 in the update in week 1 September 2005. No new studies were found in the update in September 2005. From the original search 15 studies initially appeared to meet the study criteria and were retrieved for further assessment. Two review authors (AJ, JS) reviewed these trials independently. Two trials met the inclusion criteria (Jenkins 1996; Issacman 1992). Thirteen studies were excluded as they did not meet the inclusion criteria. The reasons for exclusion are listed in the Table of Excluded Studies.

The participants in the two trials were parents of children who were discharged from children's hospitals, one in the United States and the other in Canada. The children in the Canadian trial (Jenkins 1996) were discharged from a Burns Unit with acute thermal injury. The children in the United States trial (Issacman 1992) were discharged from an Emergency Department with otitis media. The length of hospitalisation and the acuity of illness therefore varied between the trials. The mean age of parents in the otitis media trial (Issacman 1992) was 27 years, with the children having a mean age of 26.6 months. In the burns trial (Jenkins 1996) no mean ages of parents or children were included. Children in this trial (Jenkins 1996) were only identified as being less than 17 years of age.

The sizes of the study groups in the two trials were similar. In the otitis media trial (Issacman 1992) there was a total of 197 parents who participated and they were provided with one of three types of instruction on discharge. The control group received non standardised verbal information only $(n=84)$, one intervention group received standardised verbal instruction $(n=52)$ and the other intervention group received standardised verbal instruction plus standardised written information $(n=61)$. The burns trial (Jenkins 1996) had a total of 123 participants, and provided participants with two types of instruction on discharge. The control group was provided with routine verbal discharge instruction ( $\mathrm{n}$ $=61$ ) and the intervention group received written and verbal discharge instructions $(n=62)$. In both trials the written information was provided on discharge.

Written and verbal information versus verbal information only for patients being discharged from acute hospital settings to home 
Written information was provided in a book format for the burns trial (Jenkins 1996) and leaflet format for the otitis media trial (Issacman 1992). The otitis media trial (Issacman 1992) used the Gunning-Fog Index to ensure the readability of the information was at the fifth grade educational level or above. The burns trial (Jenkins 1996) wrote the book at fifth grade school readability level using Grammatique 5 and the Fogg index to determine readability. Parents were not involved in developing the written information in either trial.

The follow-up evaluation times varied between the two trials from 24 hours to greater than 15 days. In the otitis media trial (Issacman 1992) evaluation was conducted at discharge, and then by telephone for all participants on day one and day three following discharge. On completion of interviews on exit and day one the interviewer provided reinforcing information to the parents to correct any incorrect answers or provide missing information. The burns trial (Jenkins 1996) conducted evaluation by personal interview (120 participants) at the first outpatient appointment, and an additional three were completed by telephone interview. In this trial (Jenkins 1996) the interviews were conducted over a period between less than seven days (35.8\%), 8-14 days (35\%) and 15 plus days $(29.2 \%)$.

The trials included in the review both evaluated knowledge levels and satisfaction with discharge instructions. In the burns trial (Jenkins 1996) knowledge was measured using a ten item questionnaire with open ended questions. This required the respondents to provide information on selected burns care related topics. Parents received one point for each incorrect answer to questions about burn care. Two points were given for partially correct answers, and three points were given for correct responses, except for two questions where four points were given for a predefined optimal answer. Two other questions were used to ascertain satisfaction in this trial using a five-point Likert scale (one $=$ not at all satisfied and $5=$ completely satisfied). In the otitis media trial (Issacman 1992) knowledge was measured using a seven-item questionnaire with one point being given for each correct answer. On day three parents were asked to rate the quality of their discharge instruction on a ten point scale (ten being best) and they were also asked whether they had needed to return to an emergency department or physician for care or to seek additional medical advice by telephone. Neither trial identified if or how the tools used were validated.

\section{Risk of bias in included studies}

Allocation concealment was used to assess validity of the trials in this review. Neither of the two trials reported any concealment approach in the published articles. However on follow-up with one of the authors (Issacman 1992) the allocation concealment was provided and considered adequate. The other author (Jenkins 1996) was also contacted but did not report concealment methods, therefore adequacy of concealment was considered unclear in this trial.

Knowledge was measured at discharge and then at a period between 1 and 15 days following discharge. The otitis media trial (Issacman 1992) stated that all efforts were made to contact and interview the parent or guardian who received the discharge instruction. However, no data was collected to accurately reflect the percentage of responders who received the initial discharge instruction and who answered the follow-up questions. The burns trial (Jenkins 1996) reported that $85 \%$ of the parents who received the initial discharge instruction answered the follow-up questions. This lack of consistency in collecting and reporting who received the discharge instruction and who answered the followup questions may have resulted in the knowledge scores being underestimated.

\section{Effects of interventions}

The two trials that met the inclusion criteria provided data on the following comparisons:

\section{Comparison 5. Effect of the provision of written health information with verbal information on outpatient service care costs compared to verbal information only.}

The otitis media trial (Issacman 1992) examined the need for participants to return for additional care to the Emergency Department following discharge. This trial (Issacman 1992) found the control group (verbal information) had a statistically significant increase in need to return to the Emergency Department in comparison to the combined intervention groups (combined intervention groups $3.1 \%$ and control $10.1 \%, p<0.05$ by Fisher's exact test). This trial also examined the need to call a physician for advice following discharge and found no significant statistical difference between the three groups (standardised verbal information group $11.1 \%$, intervention group (written information in addition to verbal information) $15.1 \%$ and control $22.8 \%)$.

\section{Comparison 7. Effect of the provision of written health information with verbal information on patient/or significant other knowledge compared to verbal information only.}

In the burns trial (Jenkins 1996) the intervention group (written information in addition to verbal information) had significantly higher knowledge scores overall than those in the control group (verbal information) (average knowledge scores for intervention group 0.79 , SD 0.15 and the average knowledge scores for the control group 0.73, SD 0.16, $p=0.029)$. In the otitis media trial (Issacman 1992) knowledge scores were recorded in three areas - medication data, signs of improvement and worrisome signs. For medication data knowledge, parents in the intervention group (written information in addition to verbal information) scored significantly higher than the control group (verbal information) at exit interview (average knowledge score for intervention group 0.902 , no SD provided and the average knowledge score for the control group 0.765 no SD provided, $\mathrm{p}<0.05)$. For signs of improvement knowledge, the intervention group and the standardised verbal information group scored significantly higher than the control group at exit interview ( 0.569 (intervention group), 0.253 (standardised verbal information group) v 0.099 (control), no SD, $\mathrm{p}<0.05)$. For worrisome signs knowledge, the intervention group and the standardised verbal information group scored significantly higher than the control group at exit interview, and on day one and day three (correct or missing information had been provided after previous interviews), exit interview (0.381 (intervention group), 0.320 (standardised verbal information group) $\vee 0.055$ (control), no SD, $\mathrm{p}<0.05$ ), day one (0.445 (intervention group), 0.375 (standardised verbal information group) $v 0.191$ (control), no SD, $\mathrm{p}<0.05$ ) and day three (0.444 (intervention group), 0.387 (standardised verbal information group) v 0.224 (control), no SD, $\mathrm{p}<0.05$ ). We were unable to undertake statistical comparisons for parent knowledge as no

Written and verbal information versus verbal information only for patients being discharged from acute hospital settings to home 
standard deviations were provided by one of the trials (Issacman 1992).

\section{Comparison 10. Does the provision of written health information with verbal information improve satisfaction with inpatient services provided prior to discharge compared to verbal information only?}

Satisfaction was reported in both trials in relation to satisfaction with the discharge instructions received. Both trials reported high satisfaction scores. The burns trial (Jenkins 1996) determined the parents' satisfaction with the discharge instructions received and the usefulness of that information. Satisfaction was high in this trial (Jenkins 1996), with no significant statistical difference between the two groups (intervention 0.897, SD 0.15, control 0.914, SD 0.14). The otitis media trial (Issacman 1992) measured parent satisfaction with discharge instructions received and the results showed a higher level of satisfaction in favour of the intervention group and the standardised verbal information group (intervention group 0.96 , standardised verbal information group 0.96 and control group 0.85 , no SD given, $p<0.0001$ ). We were unable to undertake statistical comparisons for parent satisfaction as no standard deviations were provided by one of the trials (Issacman 1992).

\section{Comparison 11. Does the provision of written health information with verbal information improve adherence to recommended care compared to verbal information only?}

In the otitis media trial (Issacman 1992) used parental reporting of filling prescriptions within 24 hours of discharge as a measure of adherence to prescribed care. No significant statistical difference was shown between the three groups (intervention group 93\%, standardised verbal information group $95 \%$ and control $87 \%$, no SD given).

No trials were identified which could provide data for the following comparisions:

Comparison 1. Effect of the provision of written health information with verbal information on readmission rates compared to verbal information only.

Comparison 2. Effect of the provision of written health information with verbal information on recovery time compared to verbal information only.

Comparison 3. Effect of the provision of written health information with verbal information on complication rates compared to verbal information only.

Comparison 4. Effect of the provision of written health information with verbal information on community service costs, compared to verbal information only.

Comparison 6 . Effect of the provision of written health information with verbal information on inpatient service care costs compared to verbal information only.

Comparison 8. Effect of the provision of written health information with verbal information on confidence in one's own care management compared to verbal information only.

Comparison 9. Effect of the provision of written health information with verbal information on stress and anxiety compared to verbal information only.

Comparison 12. Do the circumstances under which the written health information with verbal information is provided influence the outcomes?
Comparison 13. Does the person providing the written health information with verbal information influence the above outcomes?

Comparison 14. Does the environment in which the written health information with verbal information is provided influence the above outcomes?

Comparison 15. Does the time before discharge in which the written health information with verbal information is provided influence the above outcomes?

\section{DISCUSSION}

This review is important because providing information to patients on discharge from hospital to home is part of everyday practice for the majority of health workers and is relevant to all consumers being discharged. There are a number of delivery formats available for providing information, the written format in addition to verbal information was specifically chosen as the focus for this review because it is the most common approach used in hospital settings at discharge.

Conclusions regarding the impact of using verbal and written health information compared to verbal information only are limited due to there only being two trials elegible for inclusion in this review and the variability of the two trials. There is some evidence to suggest that verbal and written health information when compared to verbal information only does significantly increase knowledge of parents of children with burns and otitis media being discharged from hospital to home. However, due to the lack of consistency in collecting and reporting who received the discharge instruction and who answered the follow-up questions, this may have resulted in the knowledge scores being underestimated.

Both trials reported high satisfaction with discharge instruction in the control and intervention groups. In the otitis media trial (Issacman 1992) a significantly higher score was achieved in the intervention groups compared to the control groups. It is possible these high scores are due to limitations in methods as described above, or related to the general nature of the questions asked. Studies of patient satisfaction surveys (Cohen 1996; Draper 1996) have found that asking these types of general questions mask patients' concerns or dissatifaction.

Despite these limitations, the two trials were consistent in demonstrating that verbal and written health information provided together appear to be more effective for improving knowledge and satisfaction than just providing verbal information only.

\section{Discussion of methodological processes}

Though both of these trials were measuring knowledge and satisfaction, the incompleteness of the data provided precluded the combination of data in a meta-analysis. In addition to this the methodological processes used by each trial were different, preventing the data being combined as described below.

In the burns trial (Jenkins 1996) one follow-up interview was conducted at the first outpatient visit which occurred between less than 7 and greater than 15 days following discharge (no mean time was provided). In the otitis media trial (Issacman 1992) a face to face interview was conducted at exit, followed by three followup phone interviews on day one and day three. On completion of each interview the interviewer provided reinforcing information to 
the parents to correct any incorrect answers or provide missing information. Due to this reinforcing information being provided on completion of each interview, it is only possible to consider the exit interview results in any comparison. It is not appropriate to compare the results of the first interviews in the two trials due to the large time differences (up to 15 days difference).

The types of knowledge that were tested in the two trials were quite different and this is another reason the trials cannot be combined in a meta-analysis. This is due to the different range of information required for discharge care for the diagnoses of the children (otitis media v burns). However what is important is the improved knowledge scores that have been shown in each trial between the control and intervention groups. Both trials identified that the difference in knowledge scores shown in the intervention groups could be attributed to the standardisation of the information, consistency of information provided and formalisation of the instruction process rather than necessarily the provision of written information. This is demonstrated in the otitis media trial (Issacman 1992) where improvements were shown in both the intervention groups in comparison to the control, but no significant difference between the two intervention groups. Hence the author of the otitis media trial is suggesting that it is the standardisation of the information that makes the difference to the knowledge scores. In this trial (Issacman 1992) the staff delivering the information in the two intervention groups had gone through an education training program to ensure they were familiar with the clinical condition and the important points when presenting the information to parents. This suggests that the knowledge of the practitioner on the topic and the way the supporting verbal information is delivered can also be contributing factors in improving knowledge scores. However the author of the trial did not measure or discuss this.

In the otitis media trial (Issacman 1992) the knowledge scores for 'worrisome signs' were considerably lower compared to the other knowledge scores for 'medication data' and 'signs of improvement'. The authors of this trial suggest the reasons for this could be the order in which information is presented and/or the relative importance given to the information by the parent or physician may contribute to the retention of information.

This review is narrow in its focus, being restricted to verbal and written health information compared to verbal information only at discharge from hospital to home. Despite extensive searching, it is quite possible that the review authors missed some trials that met the inclusion criteria. The literature on verbal and written health information is not well indexed because it is scattered across traditional disease boundaries. The authors invite readers to send them any studies, published or unpublished, that may meet the inclusion criteria and can be incorporated in the update.

\section{Consumer involvement}

Although consumer involvement was not part of our review objectives there is emerging evidence to say that consumer involvement leads to the production of quality information (Currie 2000; Coulter 1999; Neuhauser 1998). Both of the trials used tools to determine reading levels at the fifth grade, but did not involve consumers in the development of the written information. The use of tools to determine reading levels can be a useful measure, but does not take into consideration diverse language and cultural issues for specific groups of consumers. This was highlighted in the burns trial (Jenkins 1996) were it was indicated that Native American Indians (NAIs) who received the written information had significantly lower knowledge scores than the non-NAls. Another factor that was raised in this trial was that the culture of the health professionals providing the information and conducting the interviews may have had an impact on their knowledge and satisfaction scores, however this was not measured. This factor is important to consider in future research in this area.

\section{AUTHORS' CONCLUSIONS}

\section{Implications for practice}

This review recommends the use of both verbal and written health information when communicating about care issues with patients and/or significant others on discharge from hospital to home. The combination of verbal and written health information enables the provision of standardised care information to patients and/ or significant others, which appears to improve knowledge and satisfaction.

\section{Implications for research}

Many of our objectives could not be addressed in this review due to lack of trials which met the review's inclusion criteria. There is therefore scope for future research to investigate the effects of providing verbal and written health information on readmission rates, recovery time, complication rates, costs of health care, consumers' confidence level, stress and anxiety, adherence to recommended treatment and staff training in the delivery of verbal and written information. In addition there are other factors which impact on the effectiveness of information provided that were not considered in this review but are worthy of a separate systematic review such as the impact of patient and/or significant others being involved in the development of the written information and cultural issues around development and provision of information. Due to concerns about literacy levels for some population groups, other systematic reviews should also focus on other modes of delivery of information besides the written format.

\section{ACK N OWLEDGEMENTS}

We would like to thank Sandy Oliver for her time and expertise in advising us on the development of this review. Thankyou to Madeleine King for statistical advice and anonymous referees and editors of the Cochrane Consumers and Communication Review Group. Judy Stoelwinder assisted in developing the search strategy. Megan Kyriacou assisted by undertaking the searches and retrieving the papers for the original review, and Shirley Ward assisted by undertaking the searches in the update in September 2005. This review was peer reviewed by ten people which included all members of the Consumers and Communication Review Group editiorial team and staff, and three external referees, one of whom had consumer expertise. 


\section{RE F E R E N C E S}

\section{References to studies included in this review}

Issacman 1992 \{published and unpublished data\}

Isaacman D, Purvis K, Gyuro J, Anderson Y, Smith D. Standardized instructions: do they improve communication of discharge from the emergency department?. Pediatrics 1992;89(6):1204-7.

\section{Jenkins 1996 \{published data only\}}

Jenkins H, Blank V, Miller K, Turner J, Stanwick R. A randomized single-blind evaluation of a discharge teaching book for pediatric patients with burns. Journal of Burn Care \& Rehabilitation 1996;17(1):49-60.

\section{References to studies excluded from this review}

Delp 1996 \{published data only\}

Delp C, Jones J. Communicating information to patients: the use of cartoon illustrations to improve comprehension of instructions. Academic Emergency Medicine 1996;3(3):264-70.

\section{Esposito 1995 \{published data only\}}

Esposito $L$. The effects of medication education on adherence to medication regimes in an elderly population. Journal of Advanced Nursing 1995;21:935-43.

\section{Gibson 1995 \{published data only\}}

Gibson L. Patient education: effects of two teaching methods upon parental retention of infant feeding practices. Pediatric Nursing 1995;21(1):78-80.

\section{Hayes 1998 \{published data only\}}

Hayes K. Randomized trial of geragogy-based medication instruction in the emergency department. Nursing Research 1998;47(4):211-8.

\section{Mant 1998 \{published data only\}}

Mant J, Carter J, Wade D, Winner S. The impact of an information pack on patients with stroke and their carers: a randomised controlled trial. Clinical Rehabilitation 1998;12:465-76.

\section{Moore 2001 \{published data only\}}

Moore S, Dolansky M. Randomized trial of a home recovery intervention following coronary artery bypass surgery. Research in Nursing \& Health 2001;24:93-104.

\section{Nazareth 2002 \{published data only\}}

Nazareth I, Burton A, Shulman S, Smith P, Hains A, Timberall H. A pharmacy discharge plan for hospitalized elderly patients - a randomized controlled trial. Age and Ageing 2001;30:33-40.

\section{Regan 1995 \{published data only\}}

Regan E, Lydon-Rochell M. Effectiveness of postpartum education received by certified nurse midwives' clients at a university hospital. Journal of Nurse-Midwifery 1995;40(1):31-5.
Sharma 1995 \{published data only\}

Sharma S, Elkins D, Van Sickle A, Roberts C. Effect of predischarge interventions on aftercare attendance: process and outcome. Health and Social Work 1995;21(1):15-20.

\section{Smith 1997 \{published data only\}}

Smith L, McGowan L, Moss-Barclay C, Wheater J, Knass D, Chrystyn $\mathrm{H}$. An investigation of hospital generated pharmaceutical care when patients are discharged from hospital. British Journal of Clinical Pharmacology 1997;44:163-5.

Strobach 2000 \{published data only\}

Strobach D, Vetter-Kerkhoff C, Bogner J, Breugst W, Schlondorff D. Patient Medication Counselling [Patientenberatung zur Entlassungsmedikation]. Medizinische Klinik 2000;95:548-51.

\section{Wesseldine 1999 \{published data only\}}

Wesseldine L, McCarthy P, Silverman M. Structured discharge procedure for children admitted to hospital with acute asthma: a randomised controlled trial of nursing practice. Archives of Disease in Childhood 1999;80(12):110-6.

\section{Young 2000 \{published data only\}}

Young J, O'Connell B, McGregor S. Day surgery patients' convalescence at home: does enhanced discharge education make a difference?. Nursing and Health Sciences 2000;2:29-39.

\section{Additional references}

\section{Cohen 1996}

Cohen G, Forbes J, Garraway M. Can different patient satisfaction survey methods yield consistent results? Comparison of three surveys. BMJ 1996;313:841-4.

\section{Coulter 1999}

Coulter A, Entwistle V, Gilbert D. Sharing decisions with consumers: is the information good enough?. BMJ 1999;318:318-22.

\section{Currie 2000}

Currie K, Spink J, Rajendran M. Well-written health information: a guide. Melbourne: Department of Human Services, 2000.

\section{Devine 1995}

Devine E, Westlake S. Effects of psychoeducational care provided to adults with cancer: meta-analysis of 116 studies. Oncology Nurses Forum 1995;22(9):1369-81.

\section{Draper 1996}

Draper M, Hill S. Consumers and general practice: understanding and assessing consumers' experiences by using patient satisfaction surveys. Consumers' Health Forum of Australia 1996. 


\section{Fries 1998}

Fries J, Koop E, Sokolov J, Beadle C, Wright D. Beyond health promotion: reducing need and demand for medical care. Health Affairs 1998;17(2):70-84.

\section{Frith 1991}

Frith B. Giving information to radiotherapy patients. Nursing Standard 1991;5(34):33-5.

\section{Gibbs 1989}

Gibbs S, Waters W, George C. The benefits of prescription information leaflets. British Journal of Clinical Psychology 1989;27:723-39.

\section{Henderson 2001}

Henderson A, Zernike W. A study of the impact of discharge information for surgical patients. Journal of Advanced Nursing 2001;35(3):435-41.

\section{Johnson 1999}

Johnson A. Do parents value and use written health information?. Neonatal, Paediatric and Child Health Nursing 1999;2(1):3-7.

\section{Johnston 1993}

Johnston M, Vogele C. Benefits of psychological preparation for surgery: a meta-analysis. Annals of Behavioural Medicine 1993;15(4):245-56.

\section{Larson 1996}

Larson C, Nelson E, Gustafson D, Batalden P. The relationship between meeting patients' information needs and their satisfaction with hospital care and general health status outcomes. International Journal for Quality in Health Care 1996;8(5):447-56.

\section{Leino-Kilpi 1993}

Leino-Kilpi H, Lire L, Suominen T, Vuorenheimo J, Valimaki M. Client and information: a literature review. Journal of Clinical Nursing 1993;2(6):331-40.

\section{CHARACTERISTICS OF STUDIES}

Characteristics of included studies [ordered by study ID]

\section{Linke 1996}

Linke P. Health by information. Forum on Child and Youth Health 1996;4(1):12-14.

\section{Mamon 1992}

Mamon J, Steinwachs D, Fahey M, Bone L, Oktay J, Klein L. Impact of hospital discharge planning on meeting patient needs after returning home. Health Services Research 1992;27:155-75.

\section{Mazzuca 1982}

Mazzuca S. Does patient education in chronic disease have therapeutic value?. Journal of Chronic Disease 1982;35:521-9.

\section{Neuhauser 1998}

Neuhauser L, Schwab M, Syme SL, Bieber M, Obarski SK. Community participation in health promotion: evaluation of the California wellness guide. Health Promotion International 1998;13(3):211-22.

\section{NHMRC 2000}

National Health \& Medical Research Council. How to present the evidence for consumers: preparation of consumer publications. Canberra: Commonwealth of Australia, 2000.

\section{Nutbeam 1991}

Nutbeam D. Re-orienting health services; moving from service managment to health outcomes. Health Promotion International 1991;6(3):169-71.

\section{OECD 2001}

Organisation for Economic Cooperation and Development. Health Data. Health Data 2001 - Definitions, sources and methods. 2001.

\section{SAHC 1996}

South Australian Health Commission. Your rights and responsibilities: A charter for South Australian public health system consumers. 1996.

\section{Voepel-Lewis 1992}

Voepel-Lewis T, Andrea C, Magee S. Parent perceptions of pediatric ambulatory surgery: using family feedback for program evaluation. Journal of Post Anaesthesia Nursing 1992;7:106-14.

Issacman 1992

\begin{tabular}{ll}
\hline Methods & RCT \\
\hline Participants & US study. \\
& $\begin{array}{l}197 \text { parents of children with a mean age of 26.6 months discharged with otitis media from Children's } \\
\text { Hospital of Wisconsin Emergency Department. }\end{array}$ \\
\hline Interventions & $\begin{array}{l}\text { Control group: routine discharge teaching }(n=84) . \\
\text { Intervention group 1: standardised verbal instructions }(n=52) \text {. Intervention group 2: standardised ver- } \\
\text { bal instructions plus standard written instructions }(n=61) .\end{array}$ \\
\hline
\end{tabular}

Written and verbal information versus verbal information only for patients being discharged from acute hospital settings to home 
Issacman 1992 (Continued)

Outcomes

Knowledge of otitis media care, satisfaction with discharge instruction, outpatient service use following discharge, use of telephone advice following discharge.

Notes

Does not mention which parent answered questions - was it the same as received the instruction?

\section{Risk of bias}

\begin{tabular}{lll}
\hline Bias & Authors' judgement & Support for judgement \\
\hline Allocation concealment? & Low risk & A - Adequate \\
\hline
\end{tabular}

Jenkins 1996

\begin{tabular}{ll}
\hline Methods & RCT \\
\hline Participants & Canadian study. \\
& $\begin{array}{l}123 \text { families of children under } 17 \text { years of age, discharged with burns from Winnipeg Children's Hospi- } \\
\text { tal. }\end{array}$
\end{tabular}

\begin{tabular}{ll}
\hline Interventions & Control group: routine discharge teaching $(\mathrm{n}=61)$. \\
Intervention group: discharge instruction with the pediatric burn discharge book provided on dis- \\
charge $(\mathrm{n}=62)$.
\end{tabular}

\begin{tabular}{ll}
\hline Outcomes & Knowledge of burn care, satisfaction with discharge teaching. \\
\hline Notes & Carer who answered questionnaire not necessarily carer who received instructions.
\end{tabular}

\section{Risk of bias}

\begin{tabular}{lll}
\hline Bias & Authors' judgement & Support for judgement \\
\hline Allocation concealment? & Unclear risk & B - Unclear \\
\hline
\end{tabular}

Characteristics of excluded studies [ordered by study ID]

\begin{tabular}{ll}
\hline Study & Reason for exclusion \\
\hline Delp 1996 & RCT. Intervention - comparing two types of written information, did not include verbal information. \\
\hline Esposito 1995 & $\begin{array}{l}\text { RCT. Intervention - comparing different complexity levels of written information with varying de- } \\
\text { grees of verbal information. Verbal information only was not used as a control group. }\end{array}$ \\
\hline Gibson 1995 & $\begin{array}{l}\text { RCT. Intervention - comparing two types of verbal information and video, not compared with writ- } \\
\text { ten information. }\end{array}$ \\
\hline Hayes 1998 & $\begin{array}{l}\text { RCT. Intervention - comparing two types of written information, not compared with verbal informa- } \\
\text { tion. }\end{array}$ \\
\hline Mant 1998 & $\begin{array}{l}\text { RCT. Intervention - provided at various times not just at discharge. Intervention group provided } \\
\text { with information pack, control group provided with nothing. }\end{array}$ \\
\hline \hline Moore 2001 & RCT. Intervention - audiotape. \\
\hline \hline
\end{tabular}

Written and verbal information versus verbal information only for patients being discharged from acute hospital settings to home 


\begin{tabular}{ll}
\hline Study & Reason for exclusion \\
\hline Nazareth 2002 & $\begin{array}{l}\text { RCT. Intervention not only provided at discharge but included domiciliary assessment post dis- } \\
\text { charge. Included one long-stay hospital setting, not acute hospital setting. }\end{array}$ \\
\hline Regan 1995 & $\begin{array}{l}\text { RCT. Intervention - one group received written information only, the other group received oral in- } \\
\text { struction in addition to written instructions. Verbal information alone was not the control. }\end{array}$ \\
\hline Sharma 1995 & $\begin{array}{l}\text { Quasi-experimental. Intervention provided during admission prior to discharge. Intervention con- } \\
\text { sisted of varying degrees of information regarding follow-up appointments, not care information. }\end{array}$ \\
\hline Smith 1997 & $\begin{array}{l}\text { RCT. Intervention - both groups received written information, the experimental group received ad- } \\
\text { ditional counselling and information about a telephone help line. }\end{array}$ \\
\hline Strobach 2000 & RCT. Intervention - counselling and written information compared with no information. \\
\hline Wesseldine 1999 & $\begin{array}{l}\text { RCT. Intervention - standard care versus structured discharge package which included one on one } \\
\text { interview and written individual self management plan and booklet. }\end{array}$ \\
\hline Young 2000 & Time series design. No control group. \\
\hline
\end{tabular}

DATA AND ANALYSES

Comparison 1. Verbal and written information v verbal information

\begin{tabular}{lllll}
\hline Outcome or subgroup title & $\begin{array}{l}\text { No. of } \\
\text { studies }\end{array}$ & $\begin{array}{l}\text { No. of } \\
\text { partici- } \\
\text { pants }\end{array}$ & Statistical method & Effect size \\
\hline 1 Knowledge & 2 & 268 & Mean Difference (IV, Fixed, 95\% Cl) & $0.06[0.01,0.11]$ \\
\hline 2 Satisfaction & 2 & 211 & Mean Difference (IV, Fixed, 95\% Cl) & $-0.01[-0.06,0.04]$ \\
\hline 3 Use of outpatient treatment & 1 & 90 & Odds Ratio (M-H, Fixed, 95\% Cl) & $0.59[0.05,6.72]$ \\
\hline 4 Use of telephone advice & 1 & 90 & Odds Ratio (M-H, Fixed, 95\% Cl) & $0.83[0.24,2.85]$ \\
\hline
\end{tabular}

\section{Analysis 1.1. Comparison 1 Verbal and written information v verbal information, Outcome 1 Knowledge.}

\begin{tabular}{|c|c|c|c|c|c|c|c|}
\hline \multirow[t]{2}{*}{ Study or subgroup } & \multicolumn{2}{|c|}{ verbal and written } & \multicolumn{2}{|c|}{ verbal } & \multirow{2}{*}{$\begin{array}{c}\text { Mean Difference } \\
\text { Fixed, } 95 \% \mathrm{Cl}\end{array}$} & \multirow[t]{2}{*}{ Weight } & \multirow{2}{*}{$\begin{array}{c}\text { Mean Difference } \\
\text { Fixed, } 95 \% \mathrm{Cl}\end{array}$} \\
\hline & $\mathbf{N}$ & $\operatorname{Mean}(S D)$ & $\mathbf{N}$ & $\operatorname{Mean}(\mathrm{SD})$ & & & \\
\hline Issacman 1992 & 61 & $0.6(0)$ & 84 & $0.3(0)$ & & & Not estimable \\
\hline Total *** & 123 & & 145 & & & $100 \%$ & $0.06[0.01,0.11]$ \\
\hline \multicolumn{8}{|c|}{ Heterogeneity: Not applicable } \\
\hline \multicolumn{8}{|c|}{ Test for overall effect: $Z=2.14(P=0.03)$} \\
\hline
\end{tabular}


Analysis 1.2. Comparison 1 Verbal and written information v verbal information, Outcome 2 Satisfaction.

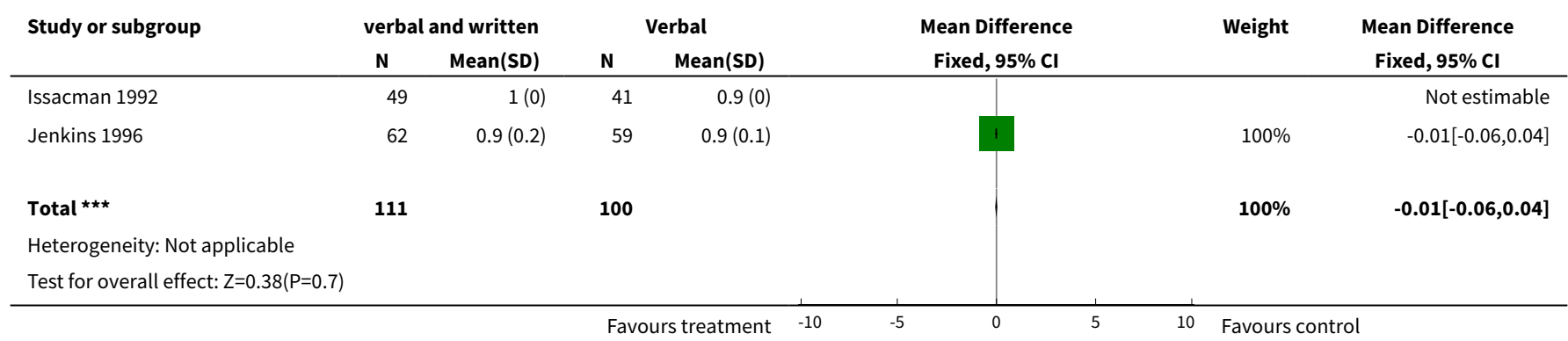

Analysis 1.3. Comparison 1 Verbal and written information v verbal information, Outcome 3 Use of outpatient treatment.

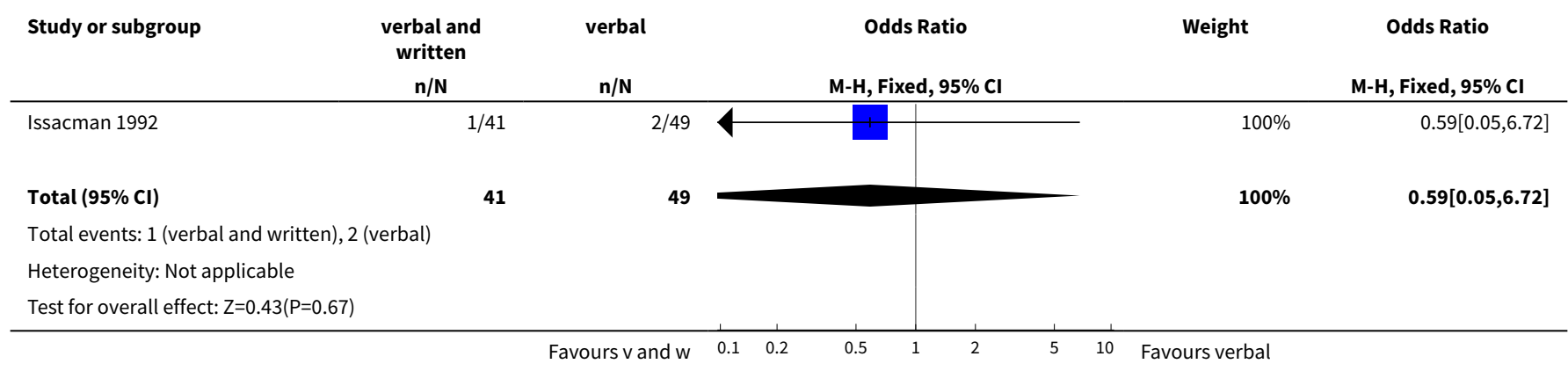

\section{Analysis 1.4. Comparison 1 Verbal and written information $v$ verbal information, Outcome 4 Use of telephone advice.}

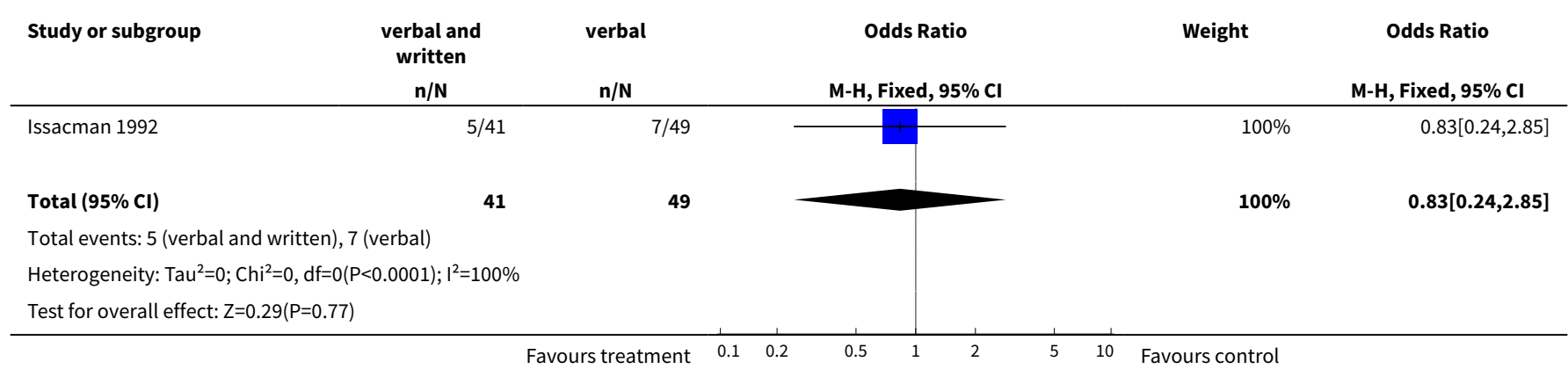

\section{APPENDICES}

\section{Appendix 1. MEDLINE (Ovid) search strategy}

1 randomized controlled trial.pt.

2 controlled clinical trial.pt.

3 randomized controlled trials/

4 random allocation/

Written and verbal information versus verbal information only for patients being discharged from acute hospital settings to home 
5 double blind method/ 6 single blind method/

7 or/1-6

$8(\mathrm{tg}=$ animals not $(\mathrm{tg}=$ human and $\mathrm{tg}=$ animals $)) \cdot \mathrm{mp} .[\mathrm{mp}=$ title, original title, abstract, name of substance word, subject heading word $]$ 97 not 8

10 clinical trials.pt.

11 exp clinical trials/

12 (clin\$ adj25 trial\$).ti.

13 (clin\$ adj25 trial\$).ab.

14 ((singl\$ or doubl\$ or trebl\$ or tripl\$) adj25 (blind\$ or mask\$)).tw.

1514 in.ti. or 14 in.ab.

16 placebos/

17 placebo\$.ti.

18 placebo\$.ab.

19 random $\$$.ti.

20 random $\$$.ab.

21 research design/

22 or/ $10-21$

237 or 22

24 exp patient discharge/

25 exp convalescence/

26 hospital discharge.tw.

27 patient discharge.tw.

28 convalescence.tw.

29 recovery.tw.

30 or/24-29)

31 (discharge adj (information or advice or education)).tw.

32 ((patient or carer or parent) adj information).tw.

33 ((patient or carer or parent) adj education).tw.

34 patient education/

35 caregiver/ed [Education]

36 exp parents/ed

37 aftercare/

38 aftercare.tw.

39 postoperative care/

40 ((postoperative or post-operative) adj care).tw.

41 continuity of patient care/

42 continuity of patient care.tw.

43 medical information.tw.

44 written information.tw.

45 pamphlets/ or pamphlet\$.tw.

46 (booklet\$ or brochure\$ or leaflet\$).tw.

47 postcards $\$ 1 . t w$.

48 or/31- 47

4930 and 48

5023 and 49

51 limit 62 to $y r=$ "2002 - 2005"

WHAT' S NEW

Date Event Description

8 July $2008 \quad$ Amended Converted to new review format.

\section{H I S T O R Y}

Protocol first published: Issue 4, 2002

Review first published: Issue 4, 2003

Written and verbal information versus verbal information only for patients being discharged from acute hospital settings to home 


\begin{tabular}{lll}
\hline Date & Event & Description \\
\hline 10 September 2005 & New search has been performed & $\begin{array}{l}\text { This Cochrane review, first published in 2003, was updated in } \\
\text { September 2005. There were no further studies identified in the } \\
\text { search. There were no comments lodged on The Cochrane Library } \\
\text { Feedback website as at 31 October 2005. }\end{array}$ \\
\hline 10 September 2005 & Amended & $\begin{array}{l}\text { Minor changes were made to the content of the review to amend } \\
\text { some minor typographical and grammatical errors. }\end{array}$ \\
\hline
\end{tabular}

\section{CONTRIBUTIONS OF AUTHORS}

Anne Johnson (AJ) is the guarantor of the review. AJ obtained funding for the review, co authored the protocol with JS, and in conjunction with JS, screened the search results, identified papers needing retrieval, screened the retrieved papers against the inclusion criteria, appraised the quality of the papers, abstracted data from the papers, contacted the authors of the papers to obtain additional data, analysed and interpreted the data and wrote the review.

Jayne Sandford (JS) co-authored the protocol with AJ and in conjunction with AJ, screened the search results, identified papers needing retrieval, screened the retrieved papers against the inclusion criteria, appraised the quality of the papers, abstracted data from the papers, contacted the authors of the papers to obtain additional data, entered data into RevMan, analysed and interpreted the data and wrote the review.

Jessica Tyndall (JT) developed the search strategies and supervised the searches.

Anne Johnson conducted the update of the review. Jessica Tyndall developed the search strategy for the update.

\section{DECLARATIONS OF INTEREST}

None known

\section{SOURCES OF SUPPORT}

\section{Internal sources}

- Flinders Medical Centre and Flinders University of South Australia, Australia.

\section{External sources}

- Bursary, Cochrane Consumers and Communication Review Group, La Trobe University, Australia.

\section{INDEX TERMS}

Medical Subject Headings (MeSH)

*Patient Discharge; *Self Care; Aftercare [ ${ }^{\star}$ methods]; Communication; Patient Education as Topic [ ${ }^{*}$ methods]

\section{MeSH check words}

Humans 